\title{
Echocardiographic epicardial fat thickness measurement: A new screening test for subclinic atherosclerosis in patients with inflammatory bowel diseases
}

\author{
Kamil Ozdil, ${ }^{1}$ Zuhal Caliskan, ${ }^{1}$ Nursen Keles, ${ }^{2}$ Oguzhan Ozturk, ${ }^{1}$ Ahmet Selami Tekin, ${ }^{2}$ \\ Resul Kahraman, ${ }^{1}$ Levent Doganay, ${ }^{1}$ Kenan Demircioglu, ${ }^{2}$ Yusuf Yilmaz, ${ }^{2}$ Mustafa Caliskan ${ }^{2}$ \\ ${ }^{1}$ Department of Gastroenterology, Saglık Bilimleri University Umraniye Training and Research Hospital, Istanbul,Turkey \\ ${ }^{2}$ Department of Cardiology, Istanbul Medeniyet University Goztepe Training and Research Hospital, Istanbul,Turkey
}

\begin{abstract}
OBJECTIVE: Inflammatory bowel diseases (IBD) consist of a number of chronic inflammatory diseases. Inflammatory process is known to be involved in all stages of atherosclerosis. Early atherosclerosis is reflected by increased levels of carotid artery intima media thickness (C-IMT) and high-sensitivity C-reactive protein (hs-CRP). Epicardial fat thickness (EFT) strongly influences both the formation and progression of atherosclerosis. Recent studies have demonstrated a relationship between c-IMT and hs-CRP levels and the risk of atherosclerosis in patients with IBD. However, no study has yet compared EFT between patients with IBD and the general healthy population. Hence, this study was designed to further evaluate whether patients with IBD have higher EFT values with increased c-IMT and hs-CRP levels compared to those in the healthy population.
\end{abstract}

METHODS: A total of 110 patients with IBD and 105 healthy volunteers were enrolled into this study. EFT was evaluated by transthoracic echocardiography. c-IMT levels were measured using an ultrasound scanner with a linear probe. The plasma levels of hs-CRP were measured using a highly sensitive sandwich ELISA technique.

RESULTS: The hs-CRP and c-IMT levels of patients with IBD were significantly higher than those of the control group. The EFT values of patients with IBD were significantly higher than those of the control group $(0.54 \pm 0.13$ vs. $0.49 \pm 0.09, p=0.002$ ).

CONCLUSION: Echocardiographic EFT measurements of patients with IBD were significantly higher than those of the normal population, which may be associated with an increased subclinical atherosclerosis risk in these patients.

Keywords: Inflammatory bowel disease; atherosclerosis; carotid intima-media thickness; high-sensitivity C-reactive protein; epicardial fat thickness.

Received: March 08, 2017 Accepted: April 10, 2017 Online: May 10, 2017

Correspondence: Dr. Nursen KELES. Istanbul Medeniyet Universitesi, Goztepe Egitim ve Arastirma Hastanesi, Kardiyoloji Klinigi, Doktor Erkin Caddesi, Kadikoy, 81130 Istanbul, Turkey.

Tel: +90 216 - 5664000 e-mail: drnursenkeles@yahoo.com.tr

(c) Copyright 2017 by Istanbul Northern Anatolian Association of Public Hospitals-Available online at www.kuzeyklinikleri.com 
$\mathrm{I}$ nflammatory bowel diseases (IBD) consist of a number of chronic diseases that are subject to relapse. In IBD, as in Crohn's disease and ulcerative colitis, an abnormal immune response occurs damaging the intestinal microvascular endothelial cells and resulting in chronic low-grade inflammation. Although IBD primarily influence the gastrointestinal system, they have been reported to affect other intestinal organs and tissues as well, including the cardiovascular $(\mathrm{CV})$ system $[1,2]$.

It is a well-established fact that inflammatory pathway activation has an important role during the induction and progression of atherosclerosis. The inflammatory cascade is known to be involved in all stages of atherosclerosis, from the early phase of endothelial dysfunction to mature atheroma formation and its subsequent rupture or erosion [3, 4]. Several studies have shown that patients with IBD may have a higher risk of developing atherosclerosis $[1,2]$.

Early atherosclerosis is reflected by increased levels of carotid artery intima media thickness (cIMT). c-IMT is a result of cumulative atherogenetic processes and may predict CV events [5].

High-sensitivity C-reactive protein (hs-CRP) is a circulating acute-phase reactant that represents active systemic inflammation and has been reported to be a strong predictor of future $\mathrm{CV}$ events in large prospective trials [6].

Epicardial fat is a true visceral adipose tissue deposited in proximity to the atrium, the right ventricle's free wall, and the left ventricular apex of the heart [7]. A recent study demonstrated that epicardial fat strongly influences both the formation and progression of coronary artery disease (CAD) [8].

Epicardial fat may also have a role in the screening of patients having intermediate CAD risk [9]. Recent studies have demonstrated an association between c-IMT and atherosclerotic risk in patients with IBD $[10,11]$. However, there are no data regarding the comparison of epicardial fat thickness (EFT) between patients with IBD and the general healthy population. The relationships between c-IMT, hs-CRP, and EFT in patients with IBD are also not yet clear.

Recently conducted trials have reported an increased risk of developing atherosclerosis in pa- tients with IBD. We hypothesized that EFT may potentially be a novel early marker of atherosclerosis along with hs-CRP and c-IMT in patients with IBD. Therefore, this study was designed to further evaluate whether patients with IBD have higher EFT values with increased c-IMT and hs-CRP levels compared to those in the healthy control group.

\section{MATERIALS AND METHODS}

\section{Study population}

Diagnoses of IBD were based on established criteria, namely, radiological, histological, clinical, and endoscopic evidence. The inclusion criterion was the patient's age being between 18 and 60 years. Each patient was examined after at least a 15-day attackfree episode [Truelove-Witts Index (TWAS)] [12] $<4$ and Crohn's Disease Activity Index (CDAI) [13] $<150)$. Exclusion criteria were the presence of congenital or valvular heart disease; any signs indicating cardiac involvement; nonsinus cardiac rhythms; any prior myocardial infarctions; hyperthyroidism or hypothyroidism; cor pulmonale or chronic obstructive pulmonary disease; diabetes mellitus; inflammatory rheumatic diseases, including rheumatoid arthritis, psoriatic arthritis, and ankylosing spondylitis; and systemic diseases such as collagenosis and hepatic, hemolytic, and renal diseases.

Moreover, subjects who used vasoactive drugs, were smokers, had a history of CAD (previous NSTEMI or angina or revascularization) or any changes in ST segments or T waves reflecting myocardial ischemia, $Q$ waves, or incidental left bundle branch block on their ECG were excluded from the study. Patients with triglyceride levels $>4.56$ $\mathrm{mmol} / \mathrm{L}(400 \mathrm{mg} / \mathrm{dL})$, body mass index (BMI) $>35 \mathrm{~kg} / \mathrm{m}^{2}$, or left ventricular mass index (LVMI) $\geq 125 \mathrm{~g} / \mathrm{m}^{2}$ for men or $110 \mathrm{~g} / \mathrm{m} 2$ for women were also excluded.

A total of 110 patients with IBD fulfilled all the inclusion and exclusion criteria and were sequentially included into the study upon their admission to our gastroenterology outpatient clinic between January 2013 and March 2016. Of the 110 patients, 56 had Crohn's disease and 54 had ulcerative colitis.

For the control group, 105 healthy volunteers, 
matched by sex and age, were recruited from volunteers and/or hospital staff. Gender, age, and BMI were recorded for each volunteer. All measurements of the patients were performed shortly after the first diagnosis of IBD.

\section{Biochemical assessments}

Levels of total serum cholesterol, low-density lipoprotein (LDL) cholesterol, triglyceride, high-density lipoprotein (HDL) cholesterol, and fasting blood glucose and erythrocyte sedimentation rate (ESR) were analyzed from blood samples of the study population. Serum hs-CRP levels were assessed by a highly sensitive sandwich ELISA technique.

The study was conducted in accordance with the guidelines of the Declaration of Helsinki on biomedical research involving human subjects. Written informed consent was received from all study subjects, and the study protocol was approved by the institutional ethics committee.

\section{Echocardiographic evaluation}

Echocardiographic evaluation of the study population was performed by a GE VIVID 7 (Horten, Norway) transthoracic echocardiography (TTE) machine. M-mode, two-dimensional, and subsequently both standard and pulsed tissue Doppler echocardiographic evaluations were performed on the study population, with patients lying laterally in the decubitus position. The diastolic interventricular septal (IVS) and posterior wall (PW) thickness and the left ventricular end-systolic diameter (LVSD) and the left ventricular end-diastolic diameter (LVDD)were measured in the parasternal long-axis window. M-mode images were used to carry out all measurements [14].

The diastolic parameters, including the early diastolic peak flow velocity $(E)$, the late diastolic peak flow velocity $(\mathrm{A})$, the $\mathrm{E} / \mathrm{A}$ ratio, and the $\mathrm{E}$-wave deceleration time (DT), were obtained by transmitral pulsed Doppler above the tips of the mitral leaflets.

The Doppler tissue-imaging (DTI) program was fixed in the pulsed-wave mode. Filters were used to exclude signals of high frequency, while the Nyquist limit conformed to the -15 to $20 \mathrm{~cm} / \mathrm{s}$ ve- locity range. Minimized gains created a legible tissue signal with a minimum background noise. The tissue Doppler measurements, including myocardial early (E) and atrial (A ) peak velocities $(\mathrm{m} / \mathrm{s}$ ) and isovolumic relaxation time (IVRT), were achieved at the apical four-chamber aspect via positioning a 5 -mm sample volume on the lateral side of the mitral annulus [14]. The IVRT was defined as the time interval between myocardial systolic wave and the onset of $\mathrm{E}$ [14]. The recording of the velocities was noted for 10 cardiac cycles at a sweep speed of $100 \mathrm{~mm} / \mathrm{s}$. All tissue Doppler measurements were performed in the course of normal respiration. The same investigator completed the echocardiographic examination while blinded to subjects' data, and two cardiologists blinded to subjects' data investigated the echocardiogram recordings.

\section{Measurement of $\mathrm{c}$-IMT}

c-IMT levels were measured by a linear probe of a Logiq 5 ultrasound scanner (General Electric Medical Systems, Wallingford, Connecticut, USA). One expert sonographer blinded to the study subjects' data performed the sonographic evaluations, with the subjects lying in the supine position in a dark, quiet room. The left common carotid arteries (CCA) were investigated with the subject's head positioned in the midline with a slight upward tilt. The probe was deployed about $1 \mathrm{~cm}$ proximally to the bifurcation of CCA, and the longitudinal plane was used to visualize the maximum lumen diameter. Distance between the media-adventitia interface and the lumen-intima interface was used to define c-IMT. Two parallel echogenic lines with an anechoic space between them can be scanned on the anterior wall of CCA [5].

\section{Measurement of EFT}

EFT was evaluated by TTE using a GE VIVID 7 (Horten, Norway) machine. EFT was measured from the parasternal long-axis view on the right ventricle's free wall at the end-diastole during three cardiac cycles.

In the parasternal long-axis window, the hypoechoic space on the right ventricular free wall was defined as EFT. The largest perpendicular distance to the aortic annulus was achieved and averaged 
TABLE1. Demographic and biochemical properties of the study population

\begin{tabular}{lcccccc} 
& $\begin{array}{c}\text { Crohn's disease } \\
(\mathrm{n}=56)\end{array}$ & $\begin{array}{c}\text { Ulcerative } \\
\text { colitis }(\mathrm{n}=54)\end{array}$ & $\begin{array}{c}\mathrm{p} 1 \\
\text { value }\end{array}$ & $\begin{array}{c}\text { IBD patients in remission } \\
\text { period }(\mathrm{n}=110)\end{array}$ & $\begin{array}{c}\text { Control group } \\
(\mathrm{n}=105)\end{array}$ & $\begin{array}{c}\mathrm{p} 2 \\
\text { value }\end{array}$ \\
\hline Age (years) & $39.4 \pm 12.2$ & $42.8 \pm 12.7$ & 0.18 & $41.1 \pm 12.6$ & $40.8 \pm 5.7$ & 0.83 \\
Male/female ( $\mathrm{n} / \mathrm{n})$ & $25 / 31$ & $24 / 30$ & 0.86 & $49 / 61$ & $59 / 56$ & 0.33 \\
Body mass index & $25.1 \pm 4.1$ & $25.5 \pm 4.6$ & 0.70 & $25.2 \pm 4.4$ & $26.7 \pm 2.56$ & 0.06 \\
Fasting blood glucose (mg/dL) & $92.4 \pm 8.9$ & $94.1 \pm 13.4$ & 0.46 & $93.1 \pm 11.3$ & $93.3 \pm 7.0$ & 0.84 \\
Total cholesterol (mg/dL) & $179.5 \pm 34.1$ & $183.1 \pm 36.4$ & 0.66 & $181.8 \pm 34.5$ & $177.7 \pm 25.4$ & 0.35 \\
Triglyceride (mg/dL) & $117.3 \pm 47.5$ & $120.6 \pm 51.9$ & 0.76 & $120.2 \pm 49.0$ & $117.5 \pm 47.9$ & 0.70 \\
HDL cholesterol (mg/dL) & $44.1 \pm 9.0$ & $45.2 \pm 9.7$ & 0.60 & $44.6 \pm 9.1$ & $45.4 \pm 10.1$ & 0.53 \\
LDL cholesterol (mg/dL) & $112.0 \pm 26.9$ & $113.7 \pm 31.8$ & 0.80 & $113.4 \pm 28.8$ & $107.9 \pm 21.0$ & 0.13 \\
Hemoglobin (mg/dL) & $13.7 \pm 1.5$ & $13.3 \pm 1.6$ & 0.21 & $13.4 \pm 1.6$ & $14.2 \pm 1.2$ & $<0.001$ \\
Hs-CRP (mg/dL) & $2.76 \pm 3.30$ & $2.45 \pm 2.72$ & 0.61 & $2.61 \pm 2.94$ & $1.36 \pm 1.24$ & $<0.001$ \\
ESR (mm/h) & $20.3 \pm 14.7$ & $18.0 \pm 13.0$ & 0.42 & $19.1 \pm 13.7$ & $13.2 \pm 8.6$ & 0.001 \\
Systolic BP (mmHg) & $119.7 \pm 13.2$ & $123.4 \pm 16.0$ & 0.23 & $123.0 \pm 15.7$ & $122.1 \pm 9.8$ & 0.56 \\
Diastolic BP (mmHg) & $74.7 \pm 6.6$ & $75.9 \pm 8.6$ & 0.44 & $75.7 \pm 8.9$ & $75.3 \pm 6.4$ & 0.73 \\
Disease duration (years) & $3.57 \pm 1.78$ & $5.75 \pm 5.61$ & 0.01 & $4.83 \pm 4.44$ & & \\
Disease activity score & $61.6 \pm 20.2$ & $3.49 \pm 0.72$ & & $61.6 \pm 20.2$ & & \\
(CDAI \& TWAS) & & & & $3.49 \pm 0.72$ & & \\
\hline
\end{tabular}

HDL: High-density lipoprotein; LDL: Low-density lipoprotein; Hs-CRP: High-sensitivity C-reactive protein; BP: Blood pressure; ESR: Erythrocyte sedimentation rate; p1: Comparison between Crohn's disease and ulcerative colitis; p2: Comparison between patients with IBD and control group.

over three cardiac cycles [15]. Intraclass correlation coefficient for echocardiographic EFT measurement was 0.94 .

\section{Statistical analyses}

All analyses were performed using the statistical software package SPSS 16.0 for Windows (SPSS Inc. Chicago, IL). The variables were examined using analytic (Kolmogorov-Smirnov or Shapiro-Wilk's test) and visual (histogram) methods by defining whether they are normally distributed. Descriptive statistics were used to summarize the data. Categorical variables were expressed as percentages, and continuous variables were expressed as mean \pm standard deviation. Differences between patients in normally and nonnormally distributed variables were evaluated by ANOVA and Kruskal-Wallis test, respectively, as appropriate. The Student's t-test was used to compare the parameters between the groups. The correlation coefficients and their significance were calculated using the Spearman's test. Kruskal-Wal- lis tests were conducted to compare parameters between the groups. The Mann-Whitney $U$ test was performed to examine the significance of pairwise differences using Bonferroni correction setting for multiple comparisons. The possible predictors identified by univariate analysis were further entered into multiple logistic regression analyses to determine the independent predictors. An overall 5\% type I error level was used to infer statistical significance.

\section{RESULTS}

\section{Study population}

The mean ages of patients with IBD (49 males and 61 females) and the healthy controls ( 59 males and 56 females) were $41.1 \pm 12.6$ and $40.8 \pm 5.7$ years, respectively, and there was no significant difference in age between the study groups $(p=0.83)$. The differences in terms of sex, BMI, and systolic and diastolic blood pressures (BP) between the two groups were also not significantly different (Table 1 ). 


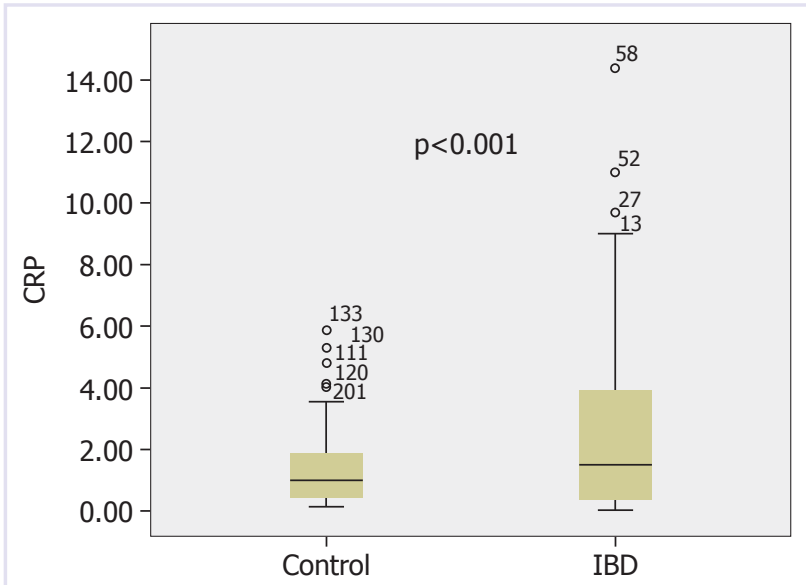

FIGURE 1. Comparison of hs-CRP levels of the study groups.

\section{Biochemical assessments}

Hs-CRP (2.61 \pm 2.94 vs. $1.36 \pm 1.24 \mathrm{mg} / \mathrm{L}, \mathrm{p}<0.001)$ and ESR (19.1 \pm 13.7 vs. $13.2 \pm 8.6, p=0.001)$ (Figure 1) values of patients with IBD were significantly higher than those of the healthy controls. However, the hemoglobin levels of patients with IBD were significantly lower than those of the healthy controls $(13.4 \pm 1.6$ vs. $14.2 \pm 1.2, p<0.001)$. The other biochemical parameters of the patients with IBD were similar to those of the healthy controls (Table 1 ).

\section{Echocardiographic evaluation}

IVS and PW thickness, left ventricular ejection fraction (EF), LVDD, LVSD, and left atrium diameter of patients with IBD were similar to those of the control group (Table 2).

Even though mitral E-wave was analogous among the groups, the differences in mitral A-wave, DT, and E/A ratio were significant between patients with IBD and the control group. Meanwhile, tissue Doppler parameters, including E, A, E / $A$ ratio, and IVRT, were also significantly different between the study subjects (Table 2). The left ventricular diastolic function parameters of patients with IBD were significantly different compared to those of healthy controls.

\section{Measurement of $\mathrm{c}$-IMT}

Patients with IBD had significantly higher c-IMT
TABLE2. Echocardiographic and ultrasonographic assessment of study population

\begin{tabular}{|c|c|c|c|}
\hline & $\begin{array}{l}\text { IBD patients in } \\
\text { remission period } \\
\quad(n=110)\end{array}$ & $\begin{array}{l}\text { Healthy } \\
\text { controls } \\
(n=105)\end{array}$ & $p$ \\
\hline IVS thickness (cm) & $0.91 \pm 0.13$ & $0.93 \pm 0.09$ & 0.31 \\
\hline PW thickness (cm) & $0.95 \pm 0.7$ & $0.91 \pm 0.08$ & 0.50 \\
\hline LVDD (cm) & $4.60 \pm 0.30$ & $4.45 \pm 0.31$ & 0.14 \\
\hline LVSD (cm) & $2.90 \pm 0.31$ & $2.88 \pm 0.22$ & 0.06 \\
\hline EF (\%) & $66.5 \pm 5.5$ & $66.2 \pm 2.6$ & 0.62 \\
\hline LAD (cm) & $3.10 \pm 0.46$ & $3.10 \pm 0.30$ & 0.65 \\
\hline $\begin{array}{l}\text { Mitral E-wave } \\
\max (\mathrm{cm} / \mathrm{s})\end{array}$ & $79.0 \pm 17.8$ & $79.3 \pm 12.4$ & 0.87 \\
\hline $\begin{array}{l}\text { Mitral A-wave } \\
\max (\mathrm{cm} / \mathrm{s})\end{array}$ & $72.1 \pm 15.1$ & $62.80 \pm 10.7$ & $<0.001$ \\
\hline DT (ms) & $209.6 \pm 43.7$ & $187.3 \pm 22.7$ & $<0.001$ \\
\hline $\mathrm{E} / \mathrm{A}$ ratio & $1.13 \pm 0.33$ & $1.31 \pm 0.21$ & 0.001 \\
\hline IVRT (ms) & $112.3 \pm 20.9$ & $107.8 \pm 9.6$ & 0.06 \\
\hline $\mathrm{E}^{\prime}(\mathrm{cm} / \mathrm{s})$ & $17.5 \pm 5.0$ & $19.6 \pm 3.5$ & 0.01 \\
\hline $\mathrm{A}^{\prime}(\mathrm{cm} / \mathrm{s})$ & $15.2 \pm 4.5$ & $13.7 \pm 3.0$ & 0.004 \\
\hline IVRT' (ms) & $96.2 \pm 23.8$ & $90.7 \pm 11.4$ & 0.03 \\
\hline$E^{\prime} / A^{\prime}$ ratio & $1.24 \pm 0.47$ & $1.48 \pm 0.39$ & $<0.001$ \\
\hline $\mathrm{EFT}(\mathrm{cm})$ & $0.54 \pm 0.13$ & $0.49 \pm 0.09$ & 0.002 \\
\hline CIMT $(\mathrm{cm})$ & $0.52 \pm 0.10$ & $0.49 \pm 0.09$ & 0.008 \\
\hline
\end{tabular}

CIMT: Carotid intima-media thickness; DT: Deceleration time; EF: Ejection fraction; EFT: Epicardial fat thickness; IBD: Inflammatory bowel disease; IVS: Interventricular septum; IVRT: Isovolumetric relaxation time; LAD: Left atrial diameter; LVDD: Left ventricular end-diastolic diameter; LVSD: Left ventricular end-systolic diameter; PW: Posterior wall.

values than those of the control group $(0.52 \pm 0.10$ vs. 0.49 $\pm 0.09, p=0.008$ ) (Table 2, Figure 2). Among the patients with IBD, 13 had carotid plaques, whereas two among the control group had carotid plaques. The proportion of carotid plaques in patients with IBD was significantly higher than that in the control group (Table 3). Patients with IBD with carotid plaques had significantly higher EFT values than those of the control group $(0.71 \pm 0.12$ vs. $0.50 \pm 0.10, \mathrm{p}<0.001)$.

\section{EFT measurement}

Patients with IBD had significantly higher EFT values than those of the control group $(0.54 \pm 0.13$ vs.0.49 $\pm 0.09, \mathrm{p}=0.002$ ) (Figure 3 ). The EFT mea- 


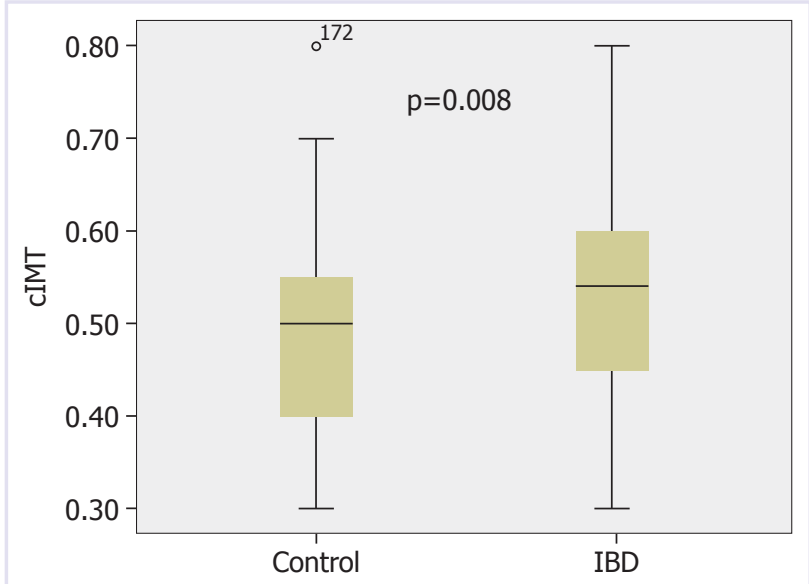

FIgURE 2. Comparison of c-IMT values of the study groups.

TABLE 3. Comparison of CIMT plaque presence in IBD patients and control group

\begin{tabular}{lccc} 
& \multicolumn{2}{c}{ CIMT plaque } & $p$ \\
\cline { 2 - 3 } & Present & Absent & \\
\hline Control & 2 & 103 & \\
IBD & 13 & 97 & 0.004 \\
Total & 15 & 200 & \\
\hline
\end{tabular}

CIMT: Carotid intima-media thickness; IBD: Inflammatory bowel disease.

surements directly correlated with c-IMT and hsCRP levels (Figures 4 and 5) in the study population. The EFT values were independent of the diffuse involvement of the gastrointestinal tract in patients with IBD (Table 4).

We also observed independent associations between EFT, hs-CRP, ESR, hemoglobin levels, and IBD via multiple logistic regression analysis (Table 5).

\section{DISCUSSION}

In the present study, we investigated whether echocardiographic EFT measurement may be used as a novel atherosclerosis predictor in patients with IBD with well-known predictors of atherosclerosis, including c-IMT and hs-CRP.

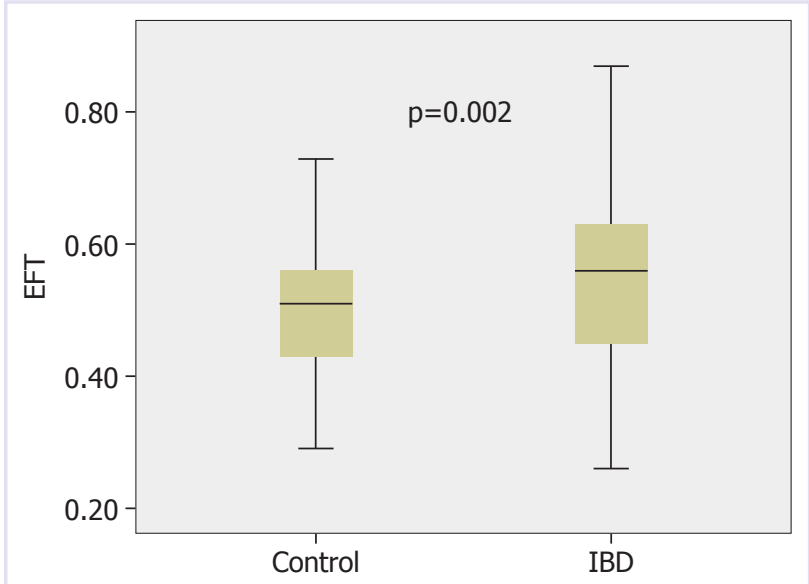

FIGURE 3. Comparison of EFT values of the study groups.

Studies have shown that inflammation plays a fundamental role in mediating all stages of atherosclerosis [4]. Chronic low-grade inflammation is involved in the pathogenesis of IBD remission period. Therefore, it is not surprising to observe that recent studies have reported that the risk of CV events increases in IBD, while the prevalence of factors traditionally associated with $\mathrm{CV}$ risk is lower than that in the general population $[1,2,16]$. The increased risk of developing atherosclerosis in patients with IBD has been demonstrated by investigating certain atherosclerotic predictors such as hs-CRP and c-IMT in some of those recent trials [17-20].

Hs-CRP is defined as a systemic marker of inflammation. Recent prospective trials have shown that the pathogenesis of atherosclerosis is associated with a chronic low-grade inflammation, and an increased hs-CRP level is described as a risk factor for CAD $[17,18]$.

Maharshak et al. [17] found that patients with Crohn's disease during the remission period have obviously elevated levels of inflammatory biomarkers, including hs-CRP and ESR. Caliskan et al. [18] also demonstrated that patients with IBD in remission have increased hs-CRP levels. We also found that hs-CRP levels in patients with IBD in the remission period were significantly higher than those in the normal population, which is consistent with previous studies. 


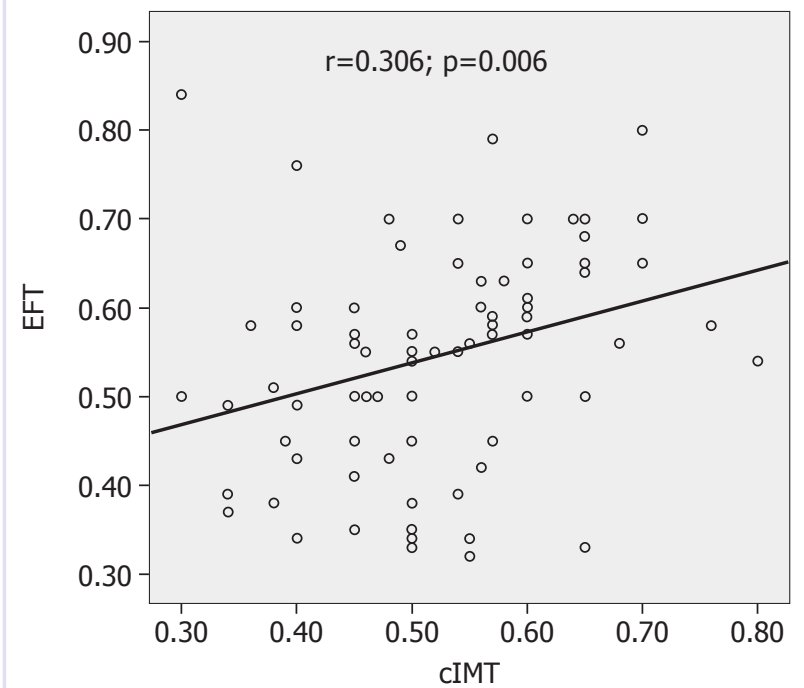

FIGURE 4. Correlation between EFT and c-IMT of the study population.

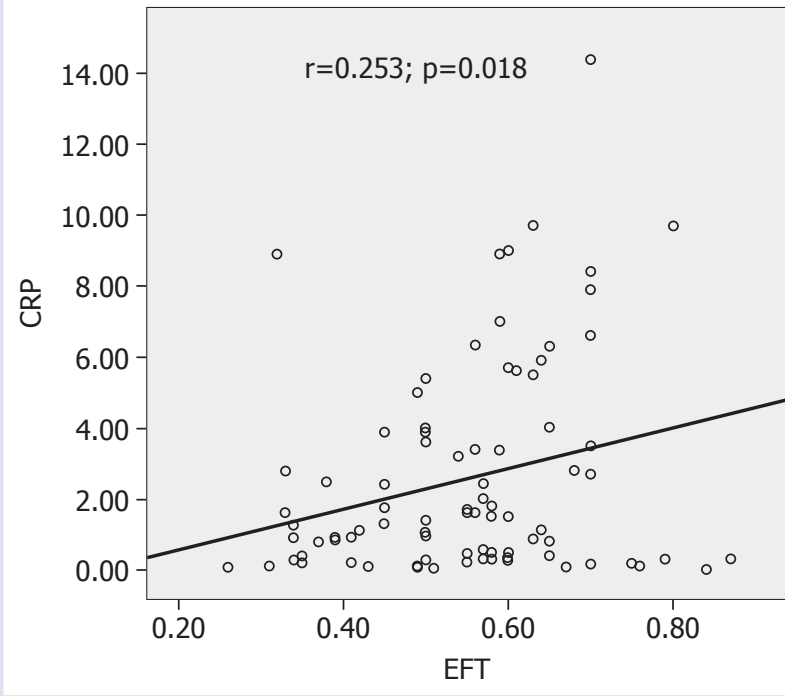

FIGURE 5. Correlation between EFT and hs-CRP of the study population.

TABLE 4. The relationship between bowel segment involvement and lipids, CIMT, and EFT values of IBD patients

\begin{tabular}{lccccccccc} 
& Terminal ileum & Ileocolic & Colic & $\mathrm{p}$ & Proctitis & Leftcolic & Diffusecolitis & Pancolitis & $\mathrm{p}$ \\
\hline Triglyceride & 115 & 126 & 110 & 0.65 & 59 & 117 & 123 & 110 & 0.65 \\
& $(74-143)$ & $(77-168)$ & $(84-155)$ & & $(56-104)$ & $(87-151)$ & $(64-170)$ & $(102-125)$ & \\
HDL & 44 & 44 & 46 & 0.82 & 47 & 46 & 42 & 42 & 0.82 \\
& $(40-49)$ & $(38-48)$ & $(37-53)$ & & $(46-48)$ & $(38-51)$ & $(38-45)$ & $(47-52)$ & \\
LDL & 105 & 110 & 123 & 0.46 & 101 & 115 & 122 & 116 & 0.46 \\
& $(96-133)$ & $(87-128)$ & $(114-150)$ & & $(95-115)$ & $102-126)$ & $(112-165)$ & $(106-131)$ & \\
EFT & 0.50 & 0.56 & 0.60 & 0.17 & 0.57 & 0.52 & 0.63 & 0.58 & 0.17 \\
& $(0.36-0.58)$ & $(0.50-0.64)$ & $(0.45-0.61)$ & & $(0.41-0.59)$ & $(0.44-0.61)$ & $(0.58-0.70)$ & $(0.50-0.70)$ & \\
CIMT & 2.3 & 2.1 & 2.5 & 0.13 & 2.5 & 2.2 & 2.1 & 2.5 & 0.13 \\
& $(2.2-2.6)$ & $(1.9-2.4)$ & $(2.3-3.3)$ & $(2.4-2.6)$ & $(2.1-2.5)$ & $(1.9-2.4)$ & $(2.3-2.8)$ & & \\
\hline
\end{tabular}

CIMT: Carotid intima-media thickness; EFT: Epicardial fat thickness; HDL: High density lipoprotein; LDL: Low density lipoprotein.

Gonzalez-Juanatey et al. [21] demonstrated that patients with rheumatoid arthritis, which is defined as a chronic inflammatory disease without evident $\mathrm{CV}$ disease, have a high frequency of left ventricular diastolic dysfunction. A previous study [18] identified LV diastolic dysfunction in patients with IBD during the remission period without having a higher burden of conventional atherosclerotic risk factors. We also found that the frequency of left ventricular diastolic dysfunction in patients with IBD is higher than that in the normal population, in agreement with findings of previous studies.

c-IMT is a measure of subclinical atherosclerosis associated with CV risk factors [6]. A meta-analysis reported that patients with rheumatoid arthritis have a statistically significantly higher c-IMT value [22]. Theocharidou et al. [11] also showed that cIMT was significantly greater in patients with IBD compared to that in healthy volunteers. Alkan et 
TABLE 5. Results of multivariate logistic regression analyses of potential predictors of inflammatory bowel disease

\begin{tabular}{lccc} 
& Odds ratio & $95 \%$ CI & $p$ \\
\hline EFT & 63.268 & $1.602-2498.543$ & 0.027 \\
C-IMT & 14.096 & $0.233-853.786$ & 0.206 \\
Hs-CRP & 1.416 & $1.105-1.813$ & 0.006 \\
ESR & 0.720 & $0.543-0.954$ & 0.022 \\
Hb & 1.039 & $1.002-1.077$ & 0.038
\end{tabular}

CI: Confidence interval; CIMT: Carotid intima-media thickness; EFT: Epicardial fat thickness; ESR: Erythrocyte sedimentation rate; Hb: Hemoglobin; Hs-CRP: High sensitivity C-reactive protein.

al. [10] also demonstrated higher values of c-IMT in patients with IBD. In the present study, we also found that c-IMT was significantly higher in patients with IBD compared to that in the healthy population, a finding in line with previous studies. Corrales et al. [23] determined the use of carotid ultrasonography for improving the stratification of the CV risk in rheumatoid arthritis. The modified EULAR systematic coronary risk evaluation (mSCORE) was used for CV risk calculation in that study. The investigators demonstrated that the presence of severe carotid US findings in patients with moderate $\mathrm{mSCORE}$ risk yielded high sensitivity for high/very high CV risk. Corrales et al. [24] also demonstrated in another study that carotid ultrasound is more sensitive than coronary artery calcification score for the evaluation of subclinical atherosclerosis in patients with rheumatoid arthritis. In our study, we also found that the ratio of carotid plaques in patients with IBD was significantly higher than that in the control group, and patients with IBD with carotid plaques had significantly higher EFT values.

Several studies have shown that the risk of developing atherosclerosis is increased in IBD by exploring a variety of atherosclerotic predictors. However, EFT has not yet been investigated as an atherosclerotic predictor in IBD.

Increased epicardial fat quantity is associated with incident CAD and major adverse CV outcomes [8]. These relationships occur independently from BMI and other conventional risk factors. Epicardial fat tissue is actually one of the factors contributing to CAD compared to other visceral fat tissues [25]. Xu et al. [26] reported that both EFT and epicardial fat tissue volumes are significantly increased in patients with CAD compared to those in the healthy group in a recent meta-analysis of 2.872 patients.

Bachar et al. [9] showed that EFT correlated strongly and positively with coronary atherosclerosis quantified by the computed tomography calcium score of 190 asymptomatic individuals with one or more factors of CV risk. A recent study demonstrated an independent relationship between arterial stiffness and EFT, suggesting that the use of echocardiographic EFT evaluation could be an easily quantifiable tool for the early determination of subclinical atherosclerosis [27].

We reported that the EFT values of patients with IBD were higher than those of the healthy control group. In the present study, the EFT measurements were independent of the diffuse involvement of the gastrointestinal tract in patients with IBD. This finding supports that low-grade chronic inflammation in IBD during remission affects the extraintestinal organs, including the CV system, independently from the gastrointestinal system involvement.

In this study, we found that the EFT values of patients with IBD directly correlated with hs-CRP levels, and there were independent associations between EFT, hs-CRP, and IBD. On the other hand, a direct correlation was found between EFT and c-IMT values. Moreover, patients with IBD having carotid plaques had significantly higher EFT values compared to those of patients with IBD without carotid plaques.

\section{Conclusion}

We found that patients with IBD had higher echocardiographic EFT values than those of the control group, and the EFT values of patients with IBD were directly related with well-defined atherosclerosis predictors such as c-IMT and hs-CRP. An association was also found between carotid plaques 
and higher EFT values. Therefore, all these findings suggest that echocardiographic EFT measurement may be used in the evaluation of CV risk along with hs-CRP and carotid ultrasound in patients with IBD.

\section{Conflict of Interest: None declared.}

Financial Disclosure: The authors declared that this study has received no financial support.

Authorship contributions: Concept - K.O.; Design - Z.C.; Supervision - M.C.; Materials - L.D.; Data collection \&/or processing - A.S.T., K.D., Y.Y.; Analysis and/or interpretation - O.O.; Literature search - R.K.; Writing - N.K.; Critical review - M.C.

\section{REFERENCES}

1. Hatoum OA, Gauthier KM, Binion DG, Miura H, Telford $\mathrm{G}$, Otterson MF, et al. Novel mechanism of vasodilation in inflammatory bowel disease. Arterioscler Thromb Vasc Biol 2005;25:2355-61.

2. Hatoum OA, Binion DG, Otterson MF, Gutterman DD. Acquired microvascular dysfunction in inflammatory bowel disease: Loss of nitric oxide-mediated vasodilation. Gastroenterology 2003;125:58-69.

3. Ross R. Atherosclerosis-an inflammatory disease. N Engl J Med 1999;340:115-26.

4. Libby P, Ridker PM, Maseri A. Inflammation and atherosclerosis. Circulation 2002;105:1135-43.

5. Yu H, Rifai N. High-sensitivity C-reactive protein and atherosclerosis: from theory to therapy. Clin Biochem 2000;33:601-10.

6. Persson J, Formgren J, Israelsson B, Berglund G. Ultrasounddetermined intima-media thickness and atherosclerosis. Direct and indirect validation. Arterioscler Thromb 1994;14:261-4.

7. Schejbal V. [Epicardial fatty tissue of the right ventricle--morphology, morphometry and functional significance]. Pneumologie 1989;43:490-9.

8. Verhagen SN, Visseren FL. Perivascular adipose tissue as a cause of atherosclerosis. Atherosclerosis 2011;214:3-10.

9. Bachar GN, Dicker D, Kornowski R, Atar E. Epicardial adipose tissue as a predictor of coronary artery disease in asymptomatic subjects. Am J Cardiol 2012;110:534-8.

10. Alkan E, Karakaş MS, Yıldırım B. Evaluation of increased subclinical atherosclerosis risk with carotid intima-media thickness and pulse wave velocity in inflamatory bowel disease. Turk J Gastroenterol 2014;25 Suppl 1:20-5.

11. Theocharidou E, Gossios TD, Griva T, Giouleme O, Douma S, Athyros VG, et al. Is there an association between inflammatory bowel diseases and carotid intima-media thickness? Preliminary data. Angiology 2014;65:543-50.

12. Truelove SC, Witts LJ. Cortisone in ulcerative colitis; final report on a therapeutic trial. Br Med J 1955;2:1041-8.

13. Best WR, Becktel JM, Singleton JW, Kern F Jr. Development of a Crohn's disease activity index. National Cooperative Crohn's
Disease Study. Gastroenterology 1976;70:439-44.

14. Sohn DW, Chai IH, Lee DJ, Kim HC, Kim HS, Oh BH, et al. Assessment of mitral annulus velocity by Doppler tissue imaging in the evaluation of left ventricular diastolic function. J Am Coll Cardiol 1997;30:474-80.

15. Iacobellis G, Ribaudo MC, Assael F, Vecci E, Tiberti C, Zappaterreno $\mathrm{A}$, et al. Echocardiographic epicardial adipose tissue is related to anthropometric and clinical parameters of metabolic syndrome: a new indicator of cardiovascular risk. J Clin Endocrinol Metab 2003;88:5163-8.

16. Yarur AJ, Deshpande AR, Pechman DM, Tamariz L, Abreu MT, Sussman DA. Inflammatory bowel disease is associated with an increased incidence of cardiovascular events. Am J Gastroenterol 2011;106:741-7.

17. Maharshak N, Zilberman L, Arbel Y, Shapira I, Berliner S, Arber $\mathrm{N}$, et al. Microinflammation in patients with Crohn's disease in clinical remission. J Crohns Colitis 2008;2:310-4.

18. Caliskan Z, Gokturk HS, Caliskan M, Gullu H, Ciftci O, Ozgur GT, et al. Impaired coronary microvascular and left ventricular diastolic function in patients with inflammatory bowel disease. Microvasc Res 2015;97:25-30.

19. Ridker PM, Hennekens CH, Buring JE, Rifai N. C-reactive protein and other markers of inflammation in the prediction of cardiovascular disease in women. N Engl J Med 2000;342:836-43.

20. Blake GJ, Ridker PM. Novel clinical markers of vascular wall inflammation. Circ Res 2001;89:763-71.

21. Gonzalez-Juanatey C, Testa A, Garcia-Castelo A, Garcia-Porrua $\mathrm{C}$, Llorca J, Ollier WE, et al. Echocardiographic and Doppler findings in long-term treated rheumatoid arthritis patients without clinically evident cardiovascular disease. Semin Arthritis Rheum 2004;33:231-8.

22. van Sijl AM, Peters MJ, Knol DK, de Vet HC, Gonzalez-Gay MA, Smulders YM, et al. Carotid intima media thickness in rheumatoid arthritis as compared to control subjects: a metaanalysis. Semin Arthritis Rheum 2011;40:389-97.

23. Corrales A, González-Juanatey C, Peiró ME, Blanco R, Llorca J, González-Gay MA. Carotid ultrasound is useful for the cardiovascular risk stratification of patients with rheumatoid arthritis: results of a population-based study. Ann Rheum Dis 2014;73:722-7.

24. Corrales A, Parra JA, González-Juanatey C, Rueda-Gotor J, Blanco R, Llorca J, et al. Cardiovascular risk stratification in rheumatic diseases: carotid ultrasound is more sensitive than Coronary Artery Calcification Score to detect subclinical atherosclerosis in patients with rheumatoid arthritis. Ann Rheum Dis 2013;72:1764-70.

25. Ding J, Hsu FC, Harris TB, Liu Y, Kritchevsky SB, Szklo M, et al. The association of pericardial fat with incident coronary heart disease: the Multi-Ethnic Study of Atherosclerosis (MESA). Am J Clin Nutr 2009;90:499-504.

26. Xu Y, Cheng X, Hong K, Huang C, Wan L. How to interpret epicardial adipose tissue as a cause of coronary artery disease: a meta-analysis. Coron Artery Dis 2012;23:227-33.

27. Kim BJ, Kim BS, Kang JH. Echocardiographic epicardial fat thickness is associated with arterial stiffness. Int J Cardiol 2013;167:2234-8. 